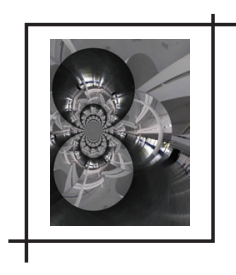

\title{
A BIENAL DE ARTE DE SÃO PAULO GERA IMPACTO NO MERCADO DE OBRAS DE ARTE BRASILEIRO?
}

\author{
Ana Paula Silva Moreno* \\ Marcos Rizolli**
}

Resumo: Este artigo busca analisar como a Bienal Internacional de Arte de São Paulo gera impacto nos negócios que incidem sobre mercado de arte brasileiro. Uma análise dos dados de exportação de obras de arte publicamente disponibilizados pelo Ministério da Indústria, Comércio Exterior e Serviços durante o período expositivo da Bienal de São Paulo (evento que geralmente ocorre de setembro a dezembro) foi realizada, e, além disso, uma pesquisa com entrevistas com galeristas de arte reconhecidos da cidade gerou novos argumentos acerca das relações entre cultura e negócios.

Palavras-chave: Bienal de Arte de São Paulo. Arte brasileira. Galerias. Mercado de arte. Negócios.

\section{INTRODUÇÃO}

Este artigo tem por objetivo analisar se a Bienal Internacional de Arte de São Paulo traz algum impacto comercial para o mercado de arte nacional. Foi realizada uma pesquisa com os dados de exportação do Ministério de Exportações a fim de entendermos se, durante o período que acontece a Bienal, a exportação de obras de arte cresce. Por meio do banco de dados do Ministério da Indústria, Comércio Exterior e Serviços (Mdic), notamos que os maiores índices de exportação têm acontecido regularmente no segundo semestre, mesmo período em que a Bienal de Arte da São Paulo está ocorrendo.

Além dos dados quantitativos, extraídos do site do Mdic do governo federal, que apresenta dados de exportações do Brasil, também acrescentamos entrevistas na metodologia de pesquisa. As entrevistas foram realizadas com profissionais da área comercial de galerias de arte e semiestruturadas, de forma individual, com três galerias de importância no Brasil. A escolha dessas galerias teve como critério o papel de liderança e existência no mercado de São Paulo.

\footnotetext{
* Mestra em Administração de Empresas com ênfase em Negócios Internacional pela Maastricht School of Management (MSM) e em Cultura Midiática pela Universidade Paulista (UNIP).E-mail: anapaula@apmstrategy.com

** Mestre e Doutor em Comunicação e Semiótica pela Pontifícia Universidade Católica de São Paulo (PUC-SP). Pós-Doutor em Artes pela Universidade Estadual Paulista (UNESP). Docente-Pesquisador no Programa de Pós-graduação em Educação, Arte e História da Cultura da Universidade Presbiteriana Mackenzie (UPM).E-mail: marcos.rizolli@mackenzie.br
} 
As entrevistas tinham o objetivo de entender como as galerias percebem o número de colecionadores internacionais na época da Bienal, explorando e comprando obras de arte brasileira.

\section{A HISTÓRIA DA BIENAL DE ARTE DE SÃO PAULO}

A Bienal de São Paulo' (antiga Bienal Internacional de Arte de São Paulo) é uma exposição de artes que ocorre a cada dois anos na cidade de São Paulo desde 1951. É considerada um dos três principais eventos do circuito artístico internacional, ao lado da Bienal de Veneza e Documenta de Kassel. É considerada a maior exposição de arte do hemisfério sul, por reunir mais de 500 mil pessoas por edição e com curadoria inovadora e foco no cenário contemporâneo. Desde sua criação, 32 bienais foram produzidas com a participação de mais de 170 países, 16 mil artistas e dez milhões de visitantes. 0 evento acontece no Pavilhão Ciccillo Matarazzo do Parque do Ibirapuera, que foi construído com todos os seus outros edifícios em 1954. 0 prédio também é conhecido como Pavilhão da Bienal e foi projetado por Oscar Niemeyer como forma de comemorar o quarto centenário da cidade de São Paulo. Em 1962, surge a Fundação Bienal de São Paulo, instituição que idealiza e coloca em prática iniciativas artísticas, educativas e sociais.

A primeira Bienal de São Paulo ocorreu (1951) graças aos esforços do empresário e mecenas Francisco Matarazzo Sobrinho (1892-1977), conhecido como Ciccillo Matarazzo, e de sua esposa Yolanda Penteado. A segunda edição (1953) ficou famosa por trazer ao Brasil a obra Guerni$c a$, de Pablo Picasso. Uma das edições mais simbólicas, contudo, foi a 10ª Bienal de São Paulo (1969), com o recém-lançado Ato Institucional n. 5 (Al-5). Nesse ano, dezenas de artistas se recusaram a participar da exposição, como Burle Marx e Hélio Oiticica, e alguns paises e regiões não apoiaram a exposição, como a União Soviética. Paralelamente, na França, cerca de 321 artistas assinaram o manifesto "Não à Bienal" - ou, em francês, "Non à la Biennale", no Museu de Arte Moderna de Paris, uma maneira de repudiar a ditadura brasileira. 0 intenso movimento pode ser compreendido pela censura à arte imposta pelo governo durante o período militar.

A Bienal é a primeira exposição de arte moderna de grande porte realizada fora dos centros culturais europeus e norte-americanos. Sua origem articula-se a uma série de outras realizações culturais em São Paulo - Museu de Arte de São Paulo Assis Chateaubriand Masp (1947), Teatro Brasileiro de Comédia - TBC (1948), Museu de Arte Moderna de São Paulo - MAM/SP (1949) e Companhia Cinematográfica Vera Cruz (1949) - que aponta para o forte impulso institucional que as artes recebem na época, beneficiado por mecenas como Ciccillo Matarazzo e Assis Chateaubriand (1892-1968). Concebida no âmbito do MAM/SP, a

1 - Disponivel em: http://www.bienal.org.br/. Acesso em: 10 out. 2018. 
$1^{\text {a }}$ Bienal é realizada em 20 de outubro de 1951 na esplanada do Trianon, local hoje ocupado pelo Masp. 0 espaço, projetado pelos arquitetos Luis Saia e Eduardo Kneese de Mello, dá lugar a 1.800 obras de 23 paises, além da representação nacional.

$\mathrm{Na}$ história da bienal, é possivel identificar quatro fases: a Era dos Museus (de 1951 a 1961), a Era do Mecenato (de 1960 a 1970), a Era dos Curadores (da 16 à 24a edição) e a Era dos Curadores Internacionais Profissionais (sua fase atual).

\section{A INTERNACIONALIZACÃO DA BIENAL DE ARTE DE SÃO PAULO}

Com a monetarização da cultura, a arte contemporânea se tornou um negócio, e, com isso, obras de arte são vistas como produtos de especulação financeira. As bienais assim se apresentam como um interessante palco de exposição. Nesse pensamento, atraem investidores de todo o mundo em busca de oportunidades de investimento. Como aquilo que é novo tem um valor menor, este pode ser mais livremente especulado, e isso significa que o risco financeiro de aquisição dessas obras é menor. Logo, trata-se de um cenário ideal para investidores que desejam diversificar suas rendas. Esse grupo explora o mundo, e as bienais se tornam paradas essenciais para esse público.

Em 2009, Chin-Tao Wu publicou um artigo na New Left Review, com referência ao estudo de Appadurai (1996), o qual identificou seis dimensões do fluxo cultural global: ethoscapes (fluxo de turistas, imigrantes, refugiados, profissionais estrangeiros com visto de trabalho etc.), mediascapes (fluxos de informação e imagens), technoscapes (de tecnologia), financespaces (financeiros), ideoscapes (fluxos de ideologias culturais e políticas) e artscapes (obras de arte).

Em relação ao artscapes, as feiras internacionais de arte são um bom exemplo disso, pois vêm crescendo rapidamente e se tornando um polo comercial, para onde os colecionadores se deslocam a fim de conhecer obras de arte e comprar com mais segurança, seguindo o grande fluxo de movimentação de outros colecionadores. Nas feiras internacionais, as galerias apresentam seus artistas, o que representa um momento estratégico de ampliação de mercado para que elas possam conhecer colecionadores de todo mundo. Com a globalização, essa massa de apreciadores de arte se desloca e se encontra ao longo do ano.

Entre as principais bienais do mundo estão as de Veneza e de São Paulo. Em 2016, a 32a Bienal de Arte de São Paulo de 2016 recebeu 900 mil visitantes.

As feiras de arte mais importantes são: The European Fine Arts Fair (Tefaf), que acontece em agosto (Maastricht), Art Basel, em junho (Basel), Art Basel Miami, em dezembro (Miami), Art Basel Hong Kong, em março (Hong Kong), Arco, em março (Barcelona), Frieze, em outubro (Londres) e Armory Show, em março (Nova York). A SP-Arte² tem aumentado de forma

2 - Disponivel em: https://www.sp-arte.com/sobre/. Acesso em: 10 out. 2018. 
significativa o número de visitantes: em 2013, teve 22.500 visitantes pagantes durante cinco dias e, em 2018, recebeu 34 mil pessoas.

0 setor brasileiro de arte contemporânea vem se estruturando para o desenvolvimento desse segmento. Em 2007, foi fundada a Associação Brasileira de Arte Contemporânea (Abact), uma entidade sem fins lucrativos que representa 50 galerias de arte contemporânea no Brasil e mais de mil artistas, com atuação no alinhamento de interesses setoriais das galerias de arte brasileiras na promoção de ações de incentivo à profissionalização e à desburocratização do mercado, de ações de educação e de promoção de diálogo entre os agentes dos mercados nacional e internacional.

Como tema deste artigo, o projeto Latitude ${ }^{3}$ é particularmente interessante por gerar um aumento no percentual de artistas que entraram pela primeira vez no mercado em 2013, em relação ao ano anterior (FIALHO, 2014). Esse programa é executado por meio de um convênio bienal de cooperação técnica e financeira firmado com a Agência Brasileira de Promoção de Exportações e Investimentos (Apex-Brasil) para a promoção internacional de projetos e negócios para o mercado brasileiro de artes.

De 2008 a 2010, as ações do Latitude centravam-se no apoio à participação de galerias brasileiras no calendário de feiras estrangeiras e na recepção de formadores de opinião internacionais e compradores de arte em eventos no Brasil, tendo a Bienal de Arte de São Paulo como um atrativo de turismo. Mais de 200 convidados internacionais, compreendendo curadores, representantes de museus, formadores de opinião, profissionais e potenciais compradores, vieram ao Brasil com seu programa Art Immersion Trip, que organiza visitas guiadas à Bienal, aos museus e às galerias de arte do país.

\section{PANORAMA DE EXPORTAÇÃO BRASILEIRA DE OBRAS DE ARTE}

No estudo para avaliarmos se Bienal de Arte de São Paulo tem algum impacto para o mercado de arte brasileiro, especificamente referente à internacionalização, avaliaremos dados de exportação brasileira de obras de arte. Na pesquisa quantitativa, os dados sobre a exportação de obras de arte de São Paulo foram retirados do site do Comex Stat ${ }^{4}$, que é um sistema para consultas e extração de dados do comércio exterior brasileiro. Mensalmente,

\footnotetext{
3 - Latitude é um programa de parceria entre a Abact e a Apex-Brasil, desenvolvido para promover a internacionalização do mercado de arte contemporânea do Brasil.

4 - 0 Comex foi estabelecido por meio da Resolução da Câmara de Comércio Exterior (Camex) n. 78, de 2 de outubro de 2013. Trata-se de serviço de solução de dúvidas que tem por finalidade atender a pedidos de informação relacionados aos seguintes assuntos pertinentes ao comércio exterior: legislação, exigências, documentos e procedimentos operacionais e técnicos relativos às operações de importação e exportação; acordos internacionais; nomenclaturas; logística, estatísticas; tributos; crédito, financiamento e apoio à exportação; promoção comercial e oportunidades de negócios.
} 
divulgam-se os dados detalhados das exportações e importações brasileiras, os quais são extraídos do Sistema Integrado de Comércio Exterior (Siscomex), um instrumento administrativo que integra as atividades de registro, acompanhamento e controle das operações de comércio exterior e que se baseia na declaração dos exportadores e importadores.

A definição do item da pesquisa foi "obra de arte" com a escolha da Nomenclatura Comum do Mercosul (NCM) ${ }^{5}$ n. 9701.10.00, a qual remete às seguintes qualificações: objetos de arte, de coleção e antiguidades, quadros, pinturas e desenhos, feitos inteiramente à mão, exceto os desenhos da posição; artigos manufaturados decorados à mão; colagens e quadros decorativos semelhantes; quadros, pinturas e desenhos.

A primeira análise objetivou identificar os principais países que importaram obras de arte do Brasil no período de 2000 a 2017. 0 resultado mostrou explicitamente que os principais paises são os Estados Unidos, o Reino Unido e a Espanha. Por meio de entrevistas qualitativas, os galeristas de arte contemporânea nos informaram que nesses paises acontecem as principais feiras de arte do mundo. Como o foco deste artigo é o papel da Bienal de Arte, não iremos nos aprofundar nessa análise das feiras.

Os resultados totais de importação foram de aproximadamente 144 milhões de dólares ao ano (Estados Unidos), 88 milhões de dólares (Reino Unido) e 31 milhões de dólares (Espanha). Outros paises tiveram resultados menos relevantes, conforme mostra o Gráfico 1.

Gráfico 1 Total de exportação de 2000 a 2017

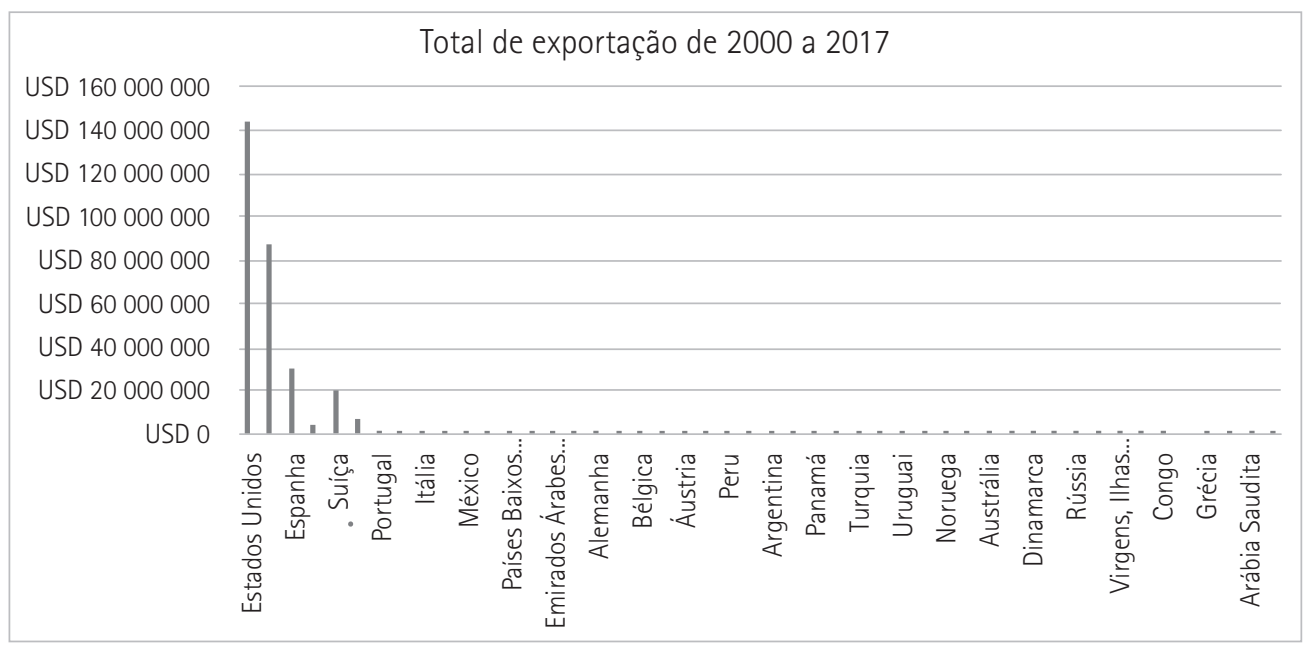

Fonte: Disponivel em: http://comexstat.mdic.gov.br/pt/home. Acesso em: 18 dez. 2019.

5 - Trata-se de um código de oito dígitos estabelecido pelo governo brasileiro para identificar a natureza das mercadorias e promover o desenvolvimento do comércio internacional, além de facilitar a coleta e análise das estatísticas do comércio exterior realizadas pela Receita Federal. 
Ao concentrarmos a pesquisa, então, nos principais paises, notamos que o índice de exportação de obras de arte aos Estados Unidos, em geral, vem crescendo ao longo dos anos.

Gráfico 2 Exportação de obras de arte aos Estados Unidos

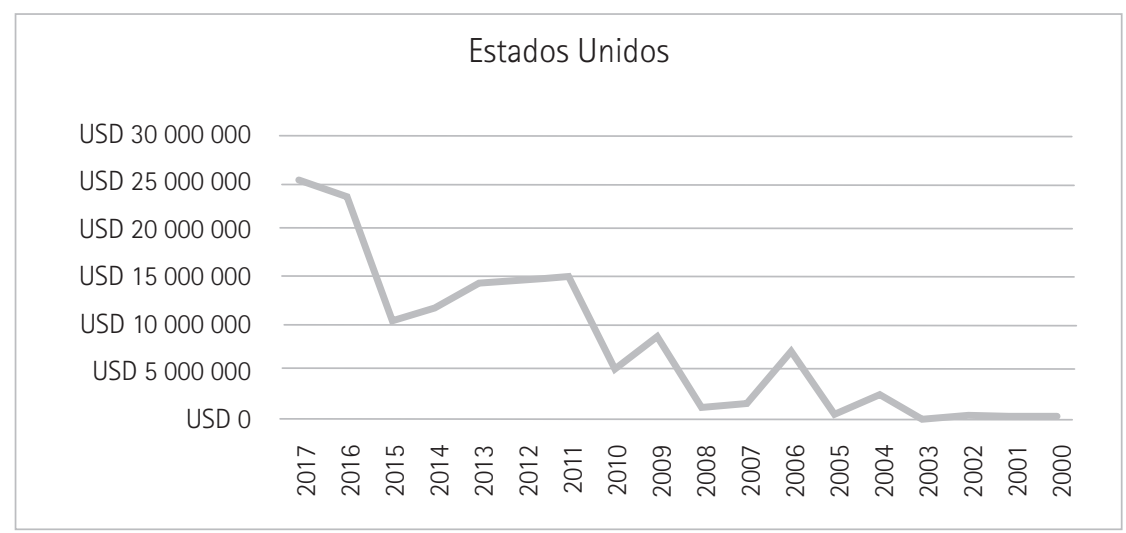

Fonte: Disponivel em: http://comexstat.mdic.gov.br/pt/home. Acesso em: 18 dez. 2019.

Já os resultados do Reino Unido apresentaram picos importantes nos anos de 2013 e 2016.

Gráfico 3 Exportação de obras de arte ao Reino Unido

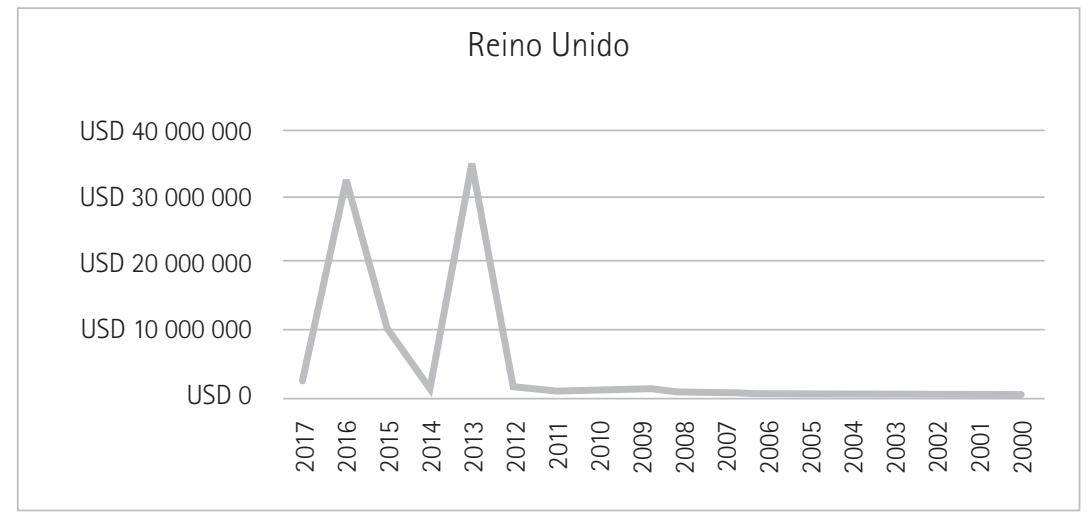

Fonte: Disponivel em: http://comexstat.mdic.gov.br/pt/home. Acesso em: 18 dez. 2019

A Espanha também apresentou anos de picos de exportação, mas o seu último foi em 2012, com uma drástica queda. 
Gráfico 4 Exportação de obras de arte à Espanha

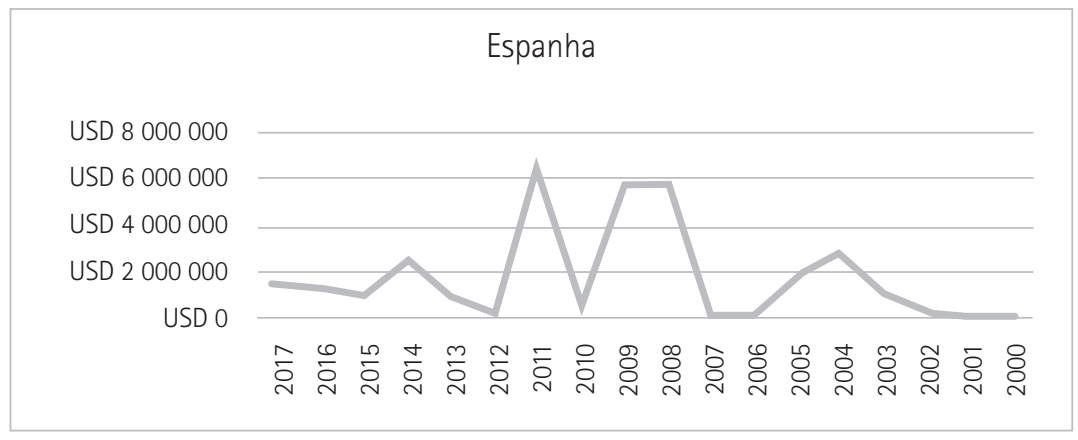

Fonte: Disponivel em: http://comexstat.mdic.gov.br/pt/home. Acesso em: 18 dez. 2019.

Quando analisamos os valores de exportação nos anos em que aconteceram as bienais de São Paulo, notamos que a Bienal não é diretamente um evento que movimenta a exportação de obras de arte e não é a razão dos picos de exportação. A ilustração dos pincéis no Gráfico 5 indica os anos em que aconteceram as bienais de arte de São Paulo.

Gráfico 5 Anos das bienais de São Paulo e valores de exportação

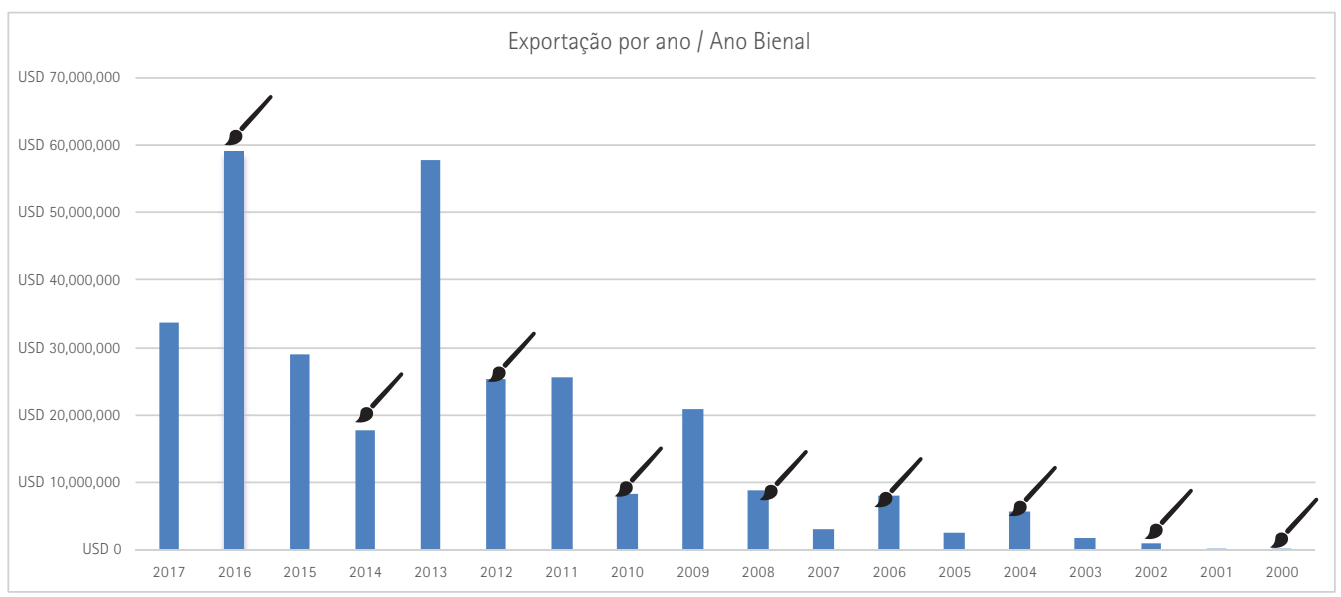

Fonte: Disponivel em: http://comexstat.mdic.gov.br/pt/home. Acesso em: 18 dez. 2019.

Realizamos um levantamento de dados de exportação por meses, especificamente do estado de São Paulo, considerando que a Bienal acontece nesse local (ver Tabela 1). Notamos que, a partir de 2009, os maiores picos de exportação de obras de arte acontecem no segundo semestre, periodo em que ocorre a Bienal. Entretanto, esses resultados não são somente nos anos das bienais. Para comparação, sinalizamos em azul as colunas em que as bienais aconteceram. 
Tabela 1 Exportação de obras de arte por meses

\begin{tabular}{|c|c|c|c|c|c|c|c|c|c|c|c|}
\hline Mês & 2017 & & 2016 & & 2015 & 2014 & 2013 & 2012 & & 2011 & 2010 \\
\hline F 01 & USD $1,885,515$ & USD 20 & 20,579 & & SD 51,100 & USD 121,231 & USD $2,428,335$ & USD 66,206 & USD & 59,791 & USD 8,975 \\
\hline F 02 & USD $2,721,357$ & USD $1,42 C$ & 20,025 & USD & $2,298,918$ & USD $3,589,352$ & USD 740,697 & USD 545,011 & USD 5,7 & 56,978 & USD 102,755 \\
\hline 703 & USD $2,287,466$ & USD 315 & 15,857 & & SD 33,000 & USD 955,430 & USD 220,932 & USD 227,937 & USD 1,1 & 45,628 & USD 320,507 \\
\hline F 04 & USD 243,381 & USD 1,18 & 89,349 & USD & 361,141 & USD $1,827,406$ & USD $1,410,405$ & USD 376,170 & USD & 72,823 & USD 419,402 \\
\hline F 05 & USD $3,533,470$ & USD 3,09 & 99,583 & USD 2 & $2,688,566$ & USD 224,246 & USD $1,496,978$ & USD $3,982,170$ & USD 1,0 & 43,346 & USD $1,407,046$ \\
\hline F 06 & USD 342,600 & USD 29,34 & 41,640 & USD 2 & $2,715,155$ & USD 2,509,281 & USD $2,184,342$ & USD 534,496 & USD 9 & 63,393 & USD 368,987 \\
\hline$F \quad 07$ & USD 9,132,649 & USD 1,16 & 62,782 & USD & 446,463 & USD $1,548,290$ & USD $3,646,727$ & USD 124,434 & USD 2 & 15,689 & USD 6,100 \\
\hline F 08 & USD 5,790,677 & USD 1,16 & 68,609 & & 471,349 & USD 695,459 & USD $1,517,446$ & USD 171,860 & USD & 96,417 & USD 494,824 \\
\hline F 09 & USD $2,184,674$ & USD 9,95 & 58,388 & USD $\subseteq$ & $9,464,940$ & USD 3,969,692 & USD 339,756 & USD $1,584,627$ & USD 9 & 44,779 & USD 199,855 \\
\hline 10 & USD $1,160,407$ & USD 56 & 63,850 & USD 2 & $2,449,236$ & USD $1,212,985$ & USD $35,115,995$ & USD 798,805 & USD 2,1 & 23,917 & USD $3,496,212$ \\
\hline 11 & USD 3,639,298 & USD 5,55 & 51,889 & USD & 4,747 & USD 971,233 & USD 6,135,051 & USD $16,754,205$ & USD 13,0 & 14,664 & USD $1,447,829$ \\
\hline 12 & & USD 5,15 & 56,884 & &, 345 & USD 43,700 & & USD 72,051 & Ds & 490 & USD 3,609 \\
\hline SP: & USD $33,802,903$ & USD 58,951 & 1,451 & USD 28 & 980,975 & USD $17,670,319$ & USD $57,828,541$ & USD $25,239,984$ & USD 25,53 & 926 & USD $8,277,931$ \\
\hline Mês & 2009 & 2008 & & 2007 & & 2005 & 2004 & 2003 & 2002 & & 2000 \\
\hline 01 & USD 295,555 & USD $1,398,719$ & & 33,853 & USD 1,425 & USD 258,400 & USD $2,613,332$ & USD 73,688 & USD 215,914 & USD & USD 4,988 \\
\hline 02 & USD 5,731,987 & USD $4,559,963$ & & 30,893 & USD 48 & USD $1,640,533$ & USD 45,339 & USD 931,430 & USD 31,794 & USD 13 & USD 1,400 \\
\hline 03 & USD $3,508,971$ & USD 24,532 & USD & 481,432 & USD 5,245 & USD 123,765 & USD 44,113 & USD 497 & USD 5,760 & USD 3 & USD 4,000 \\
\hline 04 & USD 245,047 & USD 324,515 & USD & 120,863 & USD $37 C$ & USD 13,836 & USD 51,059 & USD 11,450 & USD 226,700 & USD 1 & USD 1,060 \\
\hline 05 & USD $1,589,379$ & USD 964,111 & USD & 938,897 & USD 20 & USD 45,053 & USD $1,318,653$ & USD 383,913 & USD 2,850 & USD 21 & USD 10,860 \\
\hline F 06 & USD 100,078 & USD 92,138 & USD & 167,056 & USD 13 & USD 68,426 & USD $1,088,172$ & USD 13,950 & USD 5,300 & USD 9 & USD 20,810 \\
\hline 07 & USD 100,134 & USD 109,645 & & 66,993 & USD 329 & USD 37,863 & USD 9,400 & USD 0 & USD 6,700 & USD 2 & USD 0 \\
\hline 08 & USD 58,441 & USD 99,701 & & 11,581 & USD 62 & USD 36,002 & USD 39,697 & USD 26,285 & USD 325,100 & USD 2 & USD 0 \\
\hline F 09 & USD 537,128 & USD 350,350 & USD & 258,921 & USD 65 & USD 62,199 & USD 126,973 & USD 5,075 & USD 1,586 & USD 100 & USD 202,500 \\
\hline 10 & USD 121,534 & USD 533,961 & USD & 283,351 & USD 67 & USD 80,678 & USD 43,704 & SD 164,582 & USD 83,820 & USD 3 & USD 5,000 \\
\hline 11 & USD $8,280,775$ & USD 320,917 & USD & 673,507 & USD 210 & USD 99,200 & USD 64,170 & USD 176,039 & USD 13,353 & & USD 4,321 \\
\hline 12 & USD 252,800 & USD 18,311 & & 31,429 & USD 38 & USD 67,221 & USD 270,287 & USD 17,616 & USD 35,097 & USD 17 & USD 960 \\
\hline SP: & USD $20,823,838$ & USD $8,798,871$ & USD 3,1 & 100,783 & USD 8,084 & USD $2,535,181$ & USD 5,716,903 & JSD 1,806,528 & USD 955,976 & USD 185 & USD 257,899 \\
\hline
\end{tabular}

Fonte: Disponivel em: http://comexstat.mdic.gov.br/pt/home. Acesso em: 18 dez. 2019.

De acordo com dados oficiais do programa Latitude, as galerias Latitude foram responsáveis por $41 \%$ do volume total das exportações do setor em 2016. Segundo eles, o volume das exportações do mercado brasileiro de arte vem crescendo significativamente; em 2007, foram exportados US\$ 6 milhões, e, em 2015, atingiu-se um pico de quase US\$ 70 milhões, quantia quase duas vezes maior do que a de 2014.

\section{ENTREVISTAS COM GALERISTAS DE ARTE}

As entrevistas com os galeristas de arte foram semiestruturadas e com o intuito de entender o que acontece com as galerias no periodo da Bienal, principalmente na questão de atendimento aos colecionadores estrangeiros e no quesito comercial. 0 propósito era avaliar o impacto da Bienal de Arte de São Paulo para as galerias. Para tanto, escolhemos três galerias que estão no mercado há vários anos e têm reputação e credibilidade: Nara Roesler, Baró e Millan.

Fundada em 1989 por Nara Roesler, a galeria homônima é um dos principais espaços de arte contemporânea do Brasil e representa artistas brasileiros e latino-americanos influentes da década de 1950, além de importantes artistas estabelecidos e em início de carreira. A galeria duplicou seu espaço expositivo em São Paulo em 2012 e inaugurou novos espaços no 
Rio, em 2014, e em Nova York, em 2015. Seus principais artistas representados são Abraham Palatnik, Antonio Dias, Artur Lescher, Helio Oiticica, José Patrício, Tomie Ohtake e Vik Muniz.

A Baró Galeria existe desde 2010 e é referência em arte internacional no circuito brasileiro. Dirigida pela expatriada espanhola Maria Baró, a galeria busca realçar o diálogo entre artistas, curadores, colecionadores e instituições culturais. Uma das principais exposições realizadas pela galeria foi a History of Mondrian Fanclub: Hélio Oiticica, Lygia Clark, Lygia Pape. Representa artistas importantes como Pablo Reinoso e David Medalla.

A Galeria Millan atua no mercado desde 1986 e atualmente é dirigida por André Millan e Socorro de Andrade Lima. Em 2015, inaugurou o Anexo Millan, um espaço expositivo de 450 $\mathrm{m}^{2}$ para abrigar projetos mais audaciosos dos artistas representados. Desde a fundação, a galeria procura estabelecer diálogos entre a produção de artistas modernos e sua contribuição para a formação da nova geração. Seus principais artistas são Tunga, José Damasceno, Henrique Oliveira e Paulo Pasta.

\section{RESULTADOS DAS ENTREVISTAS COM GALERISTAS DE ARTE}

Para Cristiva Tolovi, que atua no mercado de arte há sete anos e trabalhou na Galeria Millan como responsável pela área comercial e institucional, a Bienal de Arte de São Paulo atrai muitos visitantes, que são, na sua maioria, profissionais da área, curadores, outros artistas e consultores. Tolovi conta também que os resultados de venda no mercado não podem ser analisados rapidamente, pois o reflexo deles não é imediato. A venda de uma obra de arte costuma passar por um longo processo de decisão do colecionador, de até um ano. Segundo Tolovi, as maiores exportações acontecem após a participação em feiras internacionais, quando as obras são levadas aos paises e vendidas. Esse fenômeno explica então o alto valor de exportação aos Estados Unidos e à Espanha, já que as principais feiras de arte contemporânea acontecem nesses paises, a Frieze, Armory, Art Basel Miami (Estados Unidos) e Arco - Feira Internacional de Arte Contemporânea (Espanha).

De acordo com Rosa Moreira, que há uma década é colecionadora e trabalha na área de vendas da Galeria Nara Roesler há três anos, a Bienal movimenta muito a cidade. No período do evento, a galeria recebe muitos profissionais estrangeiros. As galerias se preparam para recebê-los e apresentam exposições e programações especiais que incrementam as vendas.

Segundo Martin Bernard, um dos sócios da Galeria Baró, a Bienal de Arte de São Paulo não influencia o mercado de obras de arte. A Abact organiza visitas guiadas de estrangeiros para mostrar a arte brasileira, mas essa ação não se reverte em vendas. Deve-se ressaltar que a galeria representa artistas que tiveram suas obras expostas na Bienal e, mesmo assim, não as venderam. 


\section{CONCLUSÃO}

A partir da pesquisa realizada, podemos concluir que a Bienal de Arte de São Paulo traz muitos estrangeiros à cidade, como curadores, colecionadores, investidores e profissionais diversos. Durante a Bienal, organizam-se várias visitas guiadas e eventos paralelos nas galerias de arte, na tentativa de incrementar as vendas.

Entretanto, de acordo com os dados oficiais de exportação do Ministério de Comércio brasileiro, não é a Bienal de Arte que impulsiona a exportação de obras de arte diretamente. $\mathrm{Na}$ verdade, os picos de exportação de obras de arte estão relacionados às feiras, tanto nacionais como internacionais, de que os galeristas brasileiros participam.

Se considerarmos especificamente o papel da feira de arte brasileira, a SP-Arte, os números em termos de visitação de público, participação de galerias internacionais e de negócios vêm crescendo. Em 2018, aconteceu a sua 14ª edição, de 11 a 15 de abril, no Pavilhão da Bienal, em São Paulo, que contou com a participação de 132 celebradas galerias nacionais e internacionais de arte e de 33 expositores de design, entre galerias e artistas independentes, e passaram pelo evento cerca de 34 mil pessoas. De acordo com dados fornecidos pela feira, no primeiro dia, foi vendido o total de 4,8 milhões de reais, apenas para uma das galerias participantes.

Em termos internacionais, os dados de exportação mostram a relação direta principalmente com os países onde acontecem as maiores feiras de arte contemporânea do mundo, como Estados Unidos, Espanha e Reino Unido.

\section{Does the São Paulo Art Bienal generates impact in the Brazilian art market?}

Abstract: This article aims to analyze how the São Paulo Art Bienal generates business impact in the Brazilian art market. A data analysis was done on artworks exports, openly available by the Ministry of Industries, Exports \& Imports and Services, during the exhibition period of São Paulo Bienal (event which usually happens from September till December) and, in addition, a research with interviews with renown art gallerists of the city, generated new arguments about the culture and business relations.

Keywords: São Paulo Art Bienal. Brazilian art. Galleries. Art market. Business.

\section{REFERÊNCIAS}

APPADURAI, A. Modernity at large: cultural dimensions of globalization. Minneapolis: University of Minnesota Press, 1996. 
FIALHO, A. L. (coord.). Pesquisa sensorial: o mercado da arte contemporânea no Brasil. 3. ed. São Paulo: Latitude, Abact, 2014.

WU, C.-T. Biennials without borders. New Left Review, n. 57, p. 107-115, May/June 2009.

Recebido em setembro de 2018.

Aprovado em janeiro de 2019. 